\title{
'They tell you about the risks': Exploring sources of sexuality education among very young adolescents in rural Mpumalanga
}

\author{
R Essop, ${ }^{1}$ MACFS; T Tolla, ${ }^{1} \mathrm{MPH} ; \mathrm{I}$ Lynch, ${ }^{1,2} \mathrm{PhD} ;$ M Makoae, ${ }^{1} \mathrm{PhD}$ \\ Human Sciences Research Council, Cape Town, South Africa \\ ${ }^{2}$ Department of Psychology, Faculty of Humanities, Rhodes University, Grahamstown, South Africa \\ Corresponding author: REssop (REssop@hsrc.ac.za)
}

\begin{abstract}
Background. Early adolescence (ages 10 - 14) is a crucial stage of development. The importance of early intervention in improving adolescent sexual and reproductive health (SRH) is increasingly acknowledged. Yet, school-based sexuality education largely focuses on older adolescents, leaving very young adolescents to contend with conflicting information from different sources. This study responds to the need for contextually nuanced research with very young adolescents, which can inform policy and programmes aimed at improving their SRH outcomes.

Objectives. To explore very young adolescents' sources of SRH knowledge and investigate the implications of both formal school-based sexuality education and informal sources of information for their SRH rights.

Methods. This research was conducted with schoolgoing adolescents (aged 10 - 14) from the Gert Sibande district in rural Mpumalanga. Data were collected qualitatively using individual interviews and group-based participatory workshops, all conducted with the same participants. Transcribed data were analysed using thematic analysis.

Results. Findings indicate that while formal transfer of SRH information takes place through school-based sexuality education, learners' sexual knowledge is also shaped by informal sources, including household observations and sexual play. We identify three themes that cut across sources of SRH knowledge and position young adolescents in contradictory ways: prohibitive messaging, the notion of childhood innocence and everyday sexual learning.

Conclusion. Recommendations are made for comprehensive sexuality education that is responsive to this age group's needs, draws on their everyday lived experiences and optimises the opportunities offered by foregrounding agency, while remaining cognisant of structural constraints.
\end{abstract}

S Afr J Child Health 2018;12(2 Suppl 1):S36-S39. DOI:10.7196/SAJCH.2018.v12i2.1527

Young adolescence (10 - 14 years) is considered a crucial stage of development. Characterised neither as children nor entirely adolescent, this age group grapples with the many changes that social, sexual, reproductive and cognitive maturation brings. To navigate these transitions and achieve positive sexual and reproductive health (SRH) outcomes, young people require a supportive environment that relies on a responsive health system. ${ }^{[1]}$ While many young adolescents are not sexually active, when sexual activity does occur, it is more frequently associated with unequal power relationships than in older adolescents. As a result, young adolescents experience higher rates of sexual coercion, more frequent instances of agedisparate sex and more infrequent or inconsistent condom use than their older peers. ${ }^{[2,3]}$ Studies reveal that when developing children have access to quality sexuality education they are better equipped to manage and sustain their own health. ${ }^{[4,5]}$ However, the effectiveness of school-based sexuality education is hampered by the use of strict teacher-oriented approaches, a lack of practical or experiential learning methods and a strong emphasis on 'danger and disease' messaging, at the expense of addressing aspects such as dating, relationships and a positive view of sexuality. ${ }^{[6]}$

Despite increasing recognition of the importance of quality sexuality education in improving SRH outcomes for young adolescents, this age group has received little research and programmatic attention, particularly so in low- and middle-income countries, with most current literature focusing on older teens. Where research with younger adolescents does exist, findings indicate that while this age group is aware of SRH topics (such as avoiding HIV and other sexually transmitted infections (STIs), sexual violence and unwanted or unsupportable pregnancy), in-depth knowledge of these topics reflecting their everyday experiences remains low. ${ }^{[7]}$ In the absence of relatable sexuality education, young adolescents often struggle to make sense of potentially contradictory information without adult guidance. This is especially pertinent in African contexts, where there are often social taboos surrounding puberty and intergenerational communication about sexual issues, ${ }^{[8]}$ with young adolescents turning to informal sources of sexuality education. ${ }^{[9]}$

This article aims to respond to existing knowledge gaps to provide insight into how very young adolescents in South Africa (SA) receive and perceive information related to SRH and the implications of this in their lives.

\section{Methods \\ Research design}

The study took the form of qualitative participatory research, drawing on a conceptual framework of critical sexual and reproductive citizenship. ${ }^{[10]}$ This framework includes a focus on sexual agency, positioning adolescents as active agents in their SRH and engagement with the sociocultural context in which sexuality education occurs.

\section{Research setting}

Mpumalanga is a rural SA province. In addition to major health system challenges, youth in the Gert Sibande district experience many social challenges. The community is heavily affected by HIV/ AIDS and migrancy and most households rely on social grants for 
financial support. Mpumalanga is also reported to have the highest number of learners (female and male) reporting involvement in a pregnancy. ${ }^{[1]}$ Owing to the many barriers in the province for obtaining reliable modern contraceptives, an increasing number of girls and women are facing unwanted or unsupportable pregnancies.

\section{Sampling}

Purposive sampling targeted girls and boys between the ages of 10 and 14 years from schools in the Gert Sibande district in Mpumalanga. The participants were identified in primary, combined and secondary schools, with teachers assisting in recruitment of participants based on their gender, age and availability. The use of purposive sampling enabled the researchers to focus on the age group of interest in the context where they receive formal school-based sexuality education.

\section{Data collection procedure}

Learners first participated in focus group discussions conducted as four participatory workshops to create a more engaging environment. The focus groups were followed by structured individual interviews with the same cohort of participants. The groups were separated by gender and age: two groups of girls and boys from primary schools (10 - 12 years old) and two older groups (girls and boys) from high schools (13 - 14 years old). This was to ensure that learners felt comfortable to speak openly about SRH experiences among their peers of the same gender and age group. The workshops focused on four topics: (i) community SRH resources, capacities and barriers; (ii) local beliefs about SRH; (iii) dating and sex among teens, and (iv) young adolescents' SRH messages to adults. The structured individual interviews focused on similar topics, but at a more in-depth level. Group discussions and interviews were recorded for analysis.

\section{Tools}

This article reports on three of the four aforementioned participatory activities. The first activity entailed a community mapping activity to identify community SRH resources and barriers. Participants were asked to draw a map of resources and barriers in their community, which they elaborated on during a group discussion. Community mapping is an accessible way for children and young adolescents to document and reflect on 'relationships between spatial elements, cultural values and abstract ideas. ${ }^{[12]}$

The second activity was based on a discussion of 'myths and facts'. The aim was to explore participants' SRH perceptions and beliefs as shaped by their sociocultural context. ${ }^{[13]}$ The facilitator read statements exploring various SRH topics, such as puberty, menstruation, ejaculation, circumcision, contraception, abortion, and HIV and other STIs. Participants were then asked to classify each statement as being either a myth or a fact. This enabled a nonthreatening, facilitated discussion about different reasons for their responses to statements.

The third activity focused on relationships and entailed inviting participants to co-create a story based on two fictional characters: a girl called Zanele (age 12) and a boy called Themba (age 14). The story follows the girl and boy as their relationship develops, with the couple ultimately facing a decision to engage in sex. During the process of co-creating the story, participants were able to discuss normative perceptions about heterosexual dating, relationships, sexual behaviour and related decision-making.

\section{Ethics}

Ethical clearance was obtained from the Human Sciences Research Council's Research Ethics Committee (ref. no. 4/19/10/16) and permission to conduct the study in schools was obtained from the Mpumalanga Department of Basic Education. Informed parental consent and learner assent were sought and the principles of confidentiality and minimising risks were ensured throughout the process.

\section{Data analysis}

Data generated during the focus-group discussions and individual interviews were transcribed verbatim (using pseudonyms) and translated from the vernacular into English. The thematic analysis was informed by Braun and Clarke's ${ }^{[14]}$ guidelines, which focus on six phases: (i) becoming familiar with the dataset through repetitive readings; (ii) initial code generation; (iii) construction of preliminary themes; (iv) refinement of themes through comparison with coded extracts and the entire dataset; $(v)$ identifying and defining themes, and $(v i)$ developing the narrative report of the findings.

\section{Results}

A total of 33 girls and 30 boys between the ages of 10 and 14 years participated in the study. Participants were recruited from three different schools in Mpumalanga, namely one primary school, one combined school and one secondary school. All the participants identified their race as black and resided in a rural community of Greylingstad, located in the Gert Sibande district in Mpumalanga.

The most commonly reported adult sources of sexuality education listed by learners were teachers, healthcare practitioners, social workers and other community members. Learners explained that sexuality education provided by adults was delivered through the school curriculum, after-school programmes, and talks and presentations at healthcare facilities or during community-service activities. In addition to adult sources of sexuality education, learners also described informal sexuality education through sources such as peers and the media.

In what follows we present three themes that cut across different sources of sexuality education and provide insight into very young adolescents' SRH knowledge.

\section{Prohibitive messaging}

The first theme identified in learners' accounts centres on prohibitive messaging in adult communication, focused on the negative consequences associated with having sex. This echoes the 'danger and disease' messaging reported in research with older adolescents. In the following extract, learners share their perceptions of teacherled sexuality education as focused on admonishments about 'dire consequences' of early or unprotected sex.

Facilitator: 'What are you taught about sexuality in school?'

Mpho: 'They tell you about the risks involved with unprotected sex.' Nthabiseng: 'They tell you how falling pregnant can ruin your future by dropping out of school.' (Girls group, ages 11 - 12, school C, myths and facts activity)

Such cautionary messages are echoed in participants' descriptions of information shared by parents:

'[My mother] shares with me how life is, how you are supposed to... not go sleeping around with boys.' (Thandi, girl, aged 13, individual interview)

'She teaches me mostly about etiquette. I shouldn't get too used to hanging out with boys.' (Nontando, girl, aged 14, individual interview)

Notably, it was female learners who predominantly described such prohibitive messaging. This relates to widely supported societal expectations of girls and women to assume responsibility for any negative or unintended outcomes of sexual activity, in that manner removing responsibility from their male partners. However, a tension in participants' accounts is that the information provided by adults is not always easy to implement. Young adolescents are instructed to 
practise safer sex and to avoid pregnancy and HIV, yet they report that they do not always have the means to do so. We expand on this in the second theme.

\section{Childhood innocence}

A second theme in learners' accounts centres on beliefs about childhood sexual innocence and is, similar to the first theme, associated with adult sources of sexuality education. In many societies, particularly in Africa, sex issues are not discussed with adolescents. In fact, the idea of withholding sexuality information from young adolescents is seen as a way to preserve their innocence and purity. While well-intentioned, this belief fuels negative responses to young adolescents' curiosity about sex and prevents them from accessing SRH information and services. Learners described how fear of criticism and stigmatisation by healthcare providers discouraged them from accessing SRH services. This is illustrated in the following discussions, which emerged from the community mapping exercise:

Facilitator: 'Where can [girls and young women] go to get information and condoms?'

Malusi: 'Well, she can get condoms at the clinic, although they will ask her what she is doing with them.'

Buzwe: '...they never ask when older people take them, [but] they shout at young children, so it won't be easy.' (Boys group, ages 11 13 , school B, community mapping activity)

Facilitator: 'What are the obstacles or challenges that might hinder you when trying to find out information [about sex and puberty]?'

Puleng: 'Shyness, because they might question what we are doing there at such a young age.'

Lebo: 'Fear of the response you might get.' (Girls group, ages 11 - 12, school A, community mapping activity)

Societal notions of childhood innocence also shaped how young adolescents perceived parental responses to their interest in sex and dating. Participants described the need to hide sexual behaviour and relationships from parents, who considered them as being 'too young to be dating', to avoid punishment or scolding:

Facilitator: 'What about relationships [when talking to parents]?' Thulisa: '... [a girl] shouldn't go [visit a boy alone at his house] because his parents will punish them [the couple] should they find them together.'

Thembela: 'We shouldn't be kissing on street corners. We should only start relationships when we are older.' (Girls group, ages 10 - 11, school F, co-constructed story activity)

Perceptions of young adolescents as sexually naive and innocent and resultant admonishments from adults - discouraged them from discussing sex-related matters with adults. As a result, very young adolescents are left with an unfulfilled curiosity and a desire to seek this information through other sources. We discuss this in the final theme.

\section{Everyday sexual learning}

The final theme draws on young adolescents' accounts of informal sexuality education: acquired from peers, the media and household observations and through sexual play (e.g. games such as 'house house'). In this theme learners are positioned very differently compared with the two themes described earlier, which focused on sexuality education by adults. In the preceding themes, learners are cast as passive recipients of cautionary messaging about sexuality, in which sociocultural beliefs about childhood innocence function to silence young adolescent sexuality. In contrast, this final theme positions learners as active sexual 'knowers'. This theme emphasises sexual curiosity and learners' actions to obtain SRH information. It contradicts the notion that young adolescents are sexually naive, demonstrating that they produce and reproduce rich information through informal sources in their everyday life.

Learners identified conversations with peers as an opportunity to share their SRH experiences and knowledge, thereby shaping their beliefs about topics ranging from issues such as puberty to agedisparate relationships between 'blessers' and 'blessees' (transactional relationships between older men and younger women).

Mantombi: 'You shouldn't play with boys. You will bleed more [when you menstruate].' (Girls group, ages 10 - 11, school C, myths and facts activity)

Naledi: 'Blessers are old, give you money and diseases and maybe a baby, [and] then they leave you.' (Girls group, ages 11 - 12, school A, co-constructed story)

These excerpts illustrate the complexity of informal sexuality education, with participants' knowledge mirroring the cautionary tone of adult communication in some cases, but also reflect critical treatment of perceived wisdom, seen in Naledi's comment about potential exploitation in 'blesser' relationships.

Another source of young adolescents' everyday sexual learning is childhood play, which was described as involving touching or other forms of contact with the opposite gender. One of the games most reported on was 'houses', in which children act out 'adult-like' gender-specific roles, similar to that of a traditional heterosexual family. The following quotes were derived from the individual interviews.

Zimasa: 'We played "houses"...it was a home that had a mother and father and we'd manage our home like parents do.' (Girl, age 10, individual interview)

Musa: 'I played as [sic] the father because we did a lot of naughty things. We acted like adults and we kissed. We'd sleep on each other and act as if we were having sex.' (Boy, age 14, individual interview)

Finally, television, social media and the internet were also mentioned as sources of SRH information. Young adolescents increasingly have access to pornography and sexually explicit photographs and text messages, and this becomes an important source from which they learn about sex and what it 'looks' like:

Facilitator: 'What health services can you go to to learn about sex?'

Vuyo: 'I used to watch porn and it helped, at 12 midnight on Friday when everyone is sleeping [...] I heard people talking about it and I had to watch.' (Boys group, ages 13 - 14, school F, community mapping activity)

Learners' accounts of childhood sexual play and the media as a source of sexuality education not only contradict assumptions of naivety but also illustrate agentic position informed by curiosity.

\section{Discussion}

Our findings provide insights into the SRH information needs of very young adolescents and add to emerging literature in lowand middle-income countries focused on this often-overlooked group. The three themes identified in young adolescents' accounts demonstrate clear differences in the underlying assumptions about sexuality that shape adult sources of SRH information such as school-based sexuality education, compared with informal sources within young adolescents' everyday experiences. Adult sources of sexuality education largely consider young adolescents as passive recipients of information, with such education informed by a view of young adolescents as sexually naive and innocent. ${ }^{[15]}$ Our findings, however, contradict this notion and highlight that young adolescents are agentic sexual knowers, ${ }^{[2]}$ as evident from their accounts of sexuality education gleaned from informal sources such as peers and the media. 
Prohibitive, cautionary messaging in adult sources of sexuality education has implications for young adolescents' access to SRH resources. The desire to protect and ensure very young adolescents' health and safety inadvertently prevents them from accessing information and services related to sex, such as condoms or contraceptives, which they require to act on cautionary messaging. This creates a double bind for young adolescents, as they are tasked with the responsibility of ensuring healthy outcomes for their SRH but do not have access to the support and services required to do so. The findings indicate that this is particularly relevant to girls, who are often the recipients of cautionary messaging, which relay expectations of girls to avoid early or unprotected sex. Given the high incidence of coerced and age-disparate sex, this may present an untenable position for girls and young women.

Teachers, parents and other adults involved in providing sexuality education can benefit from challenging notions of childhood sexual innocence, in order to create opportunities to engage young adolescents on topics related to SRH. In SA, adults are embedded in cultures that silence young adolescents' sexuality through strict values and beliefs that shun topics of sex. Tylee et al. ${ }^{[4]}$ echo this sentiment, stating that in cultures with conservative social norms, young people facing issues such as unwanted or unsupportable pregnancies are more likely to handle these in private or with the help of friends, forgoing the resources and support adults might be able to offer.

Informal sources of sexuality education also offer opportunities for young adolescents' SRH, despite challenges associated with accuracy of information and limited adult resources and support. These everyday sources of sexual learning are rooted in the lived experiences of young adolescents and may offer valuable entry points for school-based sexuality education. Taking informal sources of sexuality education seriously and drawing these experiences into school-based efforts may help to create content that young adolescents would find more relatable. The findings bring to light a need for adult sources of sexuality education - whether at school or in the community - to capitalise on the curiosity of young adolescents and to adopt a more relatable approach to the delivery of SRH information.

\section{Study limitations}

The limitation of this study stems from the use of a purposive, convenient sample, as this limits generalisability of the study findings. With regard to study strength, the sample was relatively large for a qualitative research study.

\section{Conclusion}

In conclusion, both formal and informal forms of sexuality education are seen as valuable resources for addressing SRH concerns faced by very young adolescents. Adult-based sexuality education will benefit from acknowledging the curiosity of young adolescents and reframing them as agentic sexual knowers, to ensure they are not discouraged from accessing SRH information and services. These recommendations could be taken up in policies such as the integrated school health policy and integrated health policies addressing HIV and STIs. Organisations that work with the youth to target issues of early or unwanted pregnancy, HIV and STIs may also benefit from this research.

Acknowledgments. The authors acknowledge the dedicated research support from the HSRC AFSA project team. We would also like to thank the Asisukumeni Youth Development Centre for support during formative work and the following fieldworkers for dedicated assistance during data collection: Anna Mantombi Maboya; Lebo Puleng Motloung; Mlungisi John Nkosi; Zinhle Ntsiyane; Mcdonald Bongani Qwabe; Buyile Muareen Tshabalala; Francinah Tsotetsi. The support of the DST-NRF Centre of Excellence in Human Development towards this research is hereby acknowledged. Opinions expressed and conclusions arrived at, are those of the authors and are not necessarily to be attributed to the $\mathrm{CoE}$ in Human Development. The authors gratefully acknowledge the support of the Demography and Population Studies Programme, Schools of Public Health and Social Sciences, Faculties of Health Sciences and Humanities, University of the Witwatersrand, Johannesburg, South Africa.

Author contributions. RE conceptualised the study and drafted the manuscript. RE and TT performed the study. IL was the principal investigator MM was a co-investigator and supervised the project. All authors were involved in data analysis and interpretation, critical revision of the manuscript and the final approval of versions to be submitted.

Funding. The authors gratefully acknowledge funding received from the AIDS Foundation of South Africa (AFSA).

Conflicts of interest. None.

1. Komro KA, Flay BR, Biglan A, Promise Neighborhoods Research Consortium. Creating nurturing environments: A science-based framework for promoting child health and development within high-poverty neighborhoods. Clin Child Fam Psychol Rev 2011;14(2):111-134. https://doi.org/10.1007/s10567-0110095-2

2. Francis DA. Sexuality education in South Africa: Three essential questions. Int J Educ Dev 2010;30(3):314-319. https://doi.org/10.1016/j.ijedudev.2009.12.003

3. Shefer T, Macleod C. Life Orientation sexuality education in South Africa: Gendered norms, justice and transformation. Perspect Educ 2015;33(2):1-10.

4. Tylee A, Haller DM, Graham T, Churchill R, Sanci LA. Youth-friendly primarycare services: How are we doing and what more needs to be done? Lancet 2007;369(9572):1565-1573. https://doi.org/10.1016/s0140-6736(07)60371-7

5. Lurie M, Pronyk P, De Moor E, et al. Sexual behavior and reproductive health among HIV-infected patients in urban and rural South Africa. J Acquir Immune Defic Syndr 2008;47(4):484-493. https://doi.org/10.1097/ qai.0b013e3181648de8

6. Glover J, Macleod C. Rolling out comprehensive sexuality education in South Africa: An overview of research conducted on Life Orientation sexuality education. Unpublished policy brief document, Critical Studies in Sexualities and Reproduction. Grahamstown: Rhodes University, 2016.

7. Woog V, Kågesten A. The sexual and reproductive health needs of very young adolescents aged 10-14 in developing countries: What does the evidence show? New York: Guttmacher Institute, 2017.

8. McLaughlin C, Swartz S, Kiragu S, Walli S, Mohamed M. Old enough to know: Consulting children about sex and AIDS education in Africa. Pretoria: HSRC Press, 2012.

9. World Health Organization. Sexual and Reproductive Health: Very Young Adolescents. http://www.who.int/reproductivehealth/topics/adolescence/ very_young_ados/en/ (accessed 30 November 2017).

10. Richardson D. Claiming citizenship? Sexuality, citizenship and lesbian/feminist theory. Sexualities 2000;3(2):255-272. https://doi. org/10.1177/136346000003002009

11. Panday S, Makiwane M, Ranchod C, Letsoalo T. Teenage pregnancy in South Africa with a specific focus on school-going learners. Pretoria: Human Sciences Research Council and Department of Basic Education, 2009.

12. Blanchet-Cohen N. Taking a stance: Child agency across the dimensions of early adolescents' environmental involvement. Environ Educ Res 2008;14(3):257272. https://doi.org/10.1080/13504620802156496

13. Grassroot Soccer. Skillz girl coach's guide, v.2.3. https://www.thehealthcompass. org/project-examples/generation-skillz-coachs-guide-v23 (accessed 30 November 2017)

14. Braun V, Clarke V. Thematic analysis. In: CooperH, Camic PM, Long DL, Panter AT, Rindskopf D, Sher KJ, eds. APA Handbook of Research Methods in Psychology. Washington DC: American Psychological Association, 2012:57-71.

15. Wilson EK, Dalberth BT, Koo HP, Gard JC. Parents' perspectives on talking to preteenage children about sex. Perspect Sex Reprod Health 2010;42(1):56-63. https://doi.org/10.1363/4205610

Accepted 26 June 2018 